\title{
A review on emotional intelligence among homosexual of LGBT community
}

\begin{abstract}
This study reviews on emotional intelligence among homosexual or Lesbian, Gay, Bisexual, Transgender and Transsexual (LGBT) community. The literature was analyzed and organized according to the definitions of emotional intelligence of homosexual, in particular Lesbian, Gay, Bisexual, Transgender and Transsexual (LGBT) community in detail. Freud proposed that everyone has hidden homosexual tendencies. On the other hand, social learning theory, exert that LGBT is due to socially acceptable behavior without being punished. There are two kinds of homosexuals, such as homosexual who can sync with their ego and who cannot sync with their ego. In this review, it was known that different kind of homosexual have different phases of emotional intelligence and identity formation. Finally, practical implication was suggested for future interventional study to compare earlier phase and later phase intervention for homosexual emotional intelligence development.
\end{abstract}

Keywords: Emotional Intelligence; Homosexual; LGBT 